\title{
Comparison of various types of stiffness as predictors of the load-bearing capacity of callus tissue
}

T. Floerkemeier,

C. Hurschler,

F. Witte,

M. Wellmann,

F. Thorey,

U. Vogt,

H. Windhagen

From Hannover

Medical School,

Hannover, Germany

T. Floerkemeier, MD,

Orthopaedic Surgeon

C. Hurschler, PhD, Director

of Laboratory

F. Witte, MD, Research

Associate

M. Wellmann, MD

Orthopaedic Surgeon

F. Thorey, MD,

Orthopaedic Surgeon

H. Windhagen, MD,

Consultant Orthopaedic

Surgeon

Orthopädische Klinik der

Hannover Medical School,

Carl-Neuberg-Strasse 1

30625 Hannover, Germany.

U. Vogt, VD, Veterinary

Surgeon

Kleintierklinik der TiHo Hannover, Bünteweg 2, 30559 Hannover, Germany.

Correspondence should be sent to $\mathrm{Dr} \mathrm{H}$. Windhagen at Anna-von-Borries-Strasse 1-7, 30625 Hannover,

Germany; e-mail:

windhagen@annastift.de

(C)2005 British Editorial

Society of Bone and

Joint Surgery

doi:10.1302/0301-620X.87B12

$16247 \$ 2.00$

$J$ Bone Joint Surg [Br]

2005;87-B:1694-9.

Received 7 January 2005;

Accepted after revision

30 June 2005

The ability to predict load-bearing capacity during the consolidation phase in distraction osteogenesis by non-invasive means would represent a significant advance in the management of patients undergoing such treatment. Measurements of stiffness have been suggested as a promising tool for this purpose. Although the multidimensional characteristics of bone loading in compression, bending and torsion are apparent, most previous experiments have analysed only the relationship between maximum load-bearing capacity and a single type of stiffness. We have studied how compressive, bending and torsional stiffness are related to the torsional load-bearing capacity of healing callus using a common set of samples of bone regenerate from 26 sheep treated by tibial distraction osteogenesis.

Our findings showed that measurements of torsional, bending and compressive stiffness were all suitable as predictors of the load-bearing capacity of healing callus. Measurements of torsional stiffness performed slightly better than those of compressive and bending stiffness.

The choice of the appropriate time for removal of an external fixator is essential for the successful treatment of patients undergoing limb lengthening by means of distraction osteogenesis or in healing of a fracture. The risk of infection is increased if removal is delayed, but if it is undertaken too early there is an increased likelihood of refracture, malunion and pseudarthrosis.

Plain radiography and manual clinical examination are commonly used in clinical practice to estimate the state of the regenerative callus. Previous work has shown that plain radiography is an imprecise guide ${ }^{1-3}$ and manual testing is also inaccurate. ${ }^{4,5}$

Several methods have been proposed to predict load-bearing capacity non-invasively including dual-energy $\mathrm{x}$-ray absorptiometry, ${ }^{6-8}$ quantitative $\mathrm{CT},{ }^{8-11}$ quantitative radiography ${ }^{12}$ and ultrasound. ${ }^{13-16}$ Measurements of stiffness have been suggested for use in the quantitative adjustment of load-bearing capacity during healing because of the high correlation between the stiffness of the bone regenerate and its strength. ${ }^{17,18}$ Windhagen et $\mathrm{al}^{17}$ measured torsional stiffness in vivo and found this to be a quantitative estimate of the load-bearing capacity of the regenerate. Hente et $\mathrm{al}^{18}$ described a sensitive device to measure bending stiffness in vivo in order to assess healing of a fracture. Evans, Kenwright and Cunningham ${ }^{19}$ described a transducer to monitor the mechanical integrity of a healing fracture by measurement of stiffness in different directions. However, no comparison has been made of the suitability of the different types of stiffness to predict the capability for load bearing. It is important to know whether the various types of measurements of stiffness in vivo are all able to give information concerning the regenerate bone and its capacity for load bearing, or which is better. Nonetheless, previous work has focused only on one dimension of stiffness compression, ${ }^{13,20}$ bending ${ }^{4,13,21,22}$ or torsion ${ }^{17,23}$ with strength neglecting the characteristic multi-dimensional loading of bone. The relationship between stiffness and strength has been limited to determination of strength about one axis, i.e. compression, bending or torsion.

We have investigated how compressive, anteroposterior and mediolateral bending, and torsional stiffness are related to the torsional load-bearing capacity of healing callus using a common set of samples of bone regenerate.

\section{Materials and Methods}

We used 26 mature, female domestic sheep between two and four years of age. The animals were anaesthetised with propofol using a 


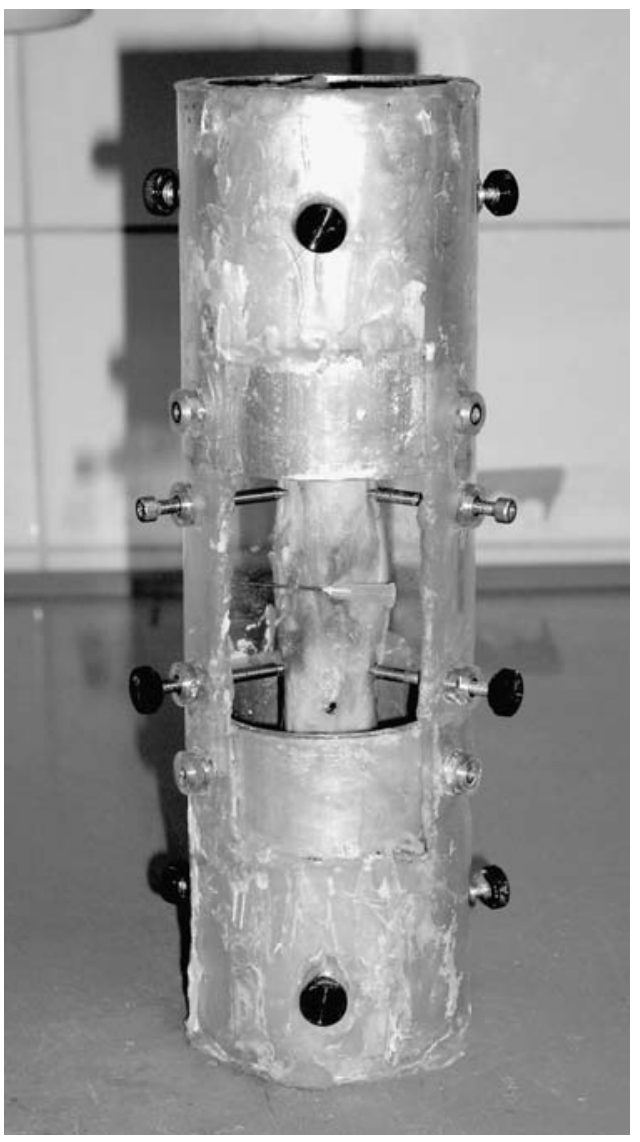

Fig. 1

Photograph of the aligning fixture used to hold the specimens before embedding of the ends. The location of the specimen is adjusted and fixed within the casting cylinder by means of six centering bolts. Embedding resin can be poured through the window in the alignment fixture.

catheter in the internal jugular vein and Isofluran and oxygen were administered through an orotracheal tube for inhalation anaesthesia.

The tibiae were stabilised using an Ilizarov external halfring fixator (Laboratory of Hannover Medical School, Hannover, Germany) mounted using six bicortical halfpins. The frame of the fixator consisted of three rings and one custom-made device for torsional measurement of in vivo stiffness connected by three rods. A mid-diaphyseal osteotomy was then performed using an oscillating saw with complete transection of the tibia. After operation the sheep were allowed to bear full weight.

Four days later lengthening began at a rate of $1.25 \mathrm{~mm}$ per day in two increments $(0.75 \mathrm{~mm}$ and $0.5 \mathrm{~mm})$ for 20 days. On the 74th day, the sheep were killed and both tibiae were disarticulated at the knee, harvested and labelled. The external fixator, the half-pins and the soft tissue were removed. Before the ends of the tibiae were embedded in polymethylmethacrylate (PMMA) (Technovit 4004, Heraeus Kulzer, Wehrheim, Germany) and frozen at $-20^{\circ} \mathrm{C}$, the distraction gap was established by radiological examination. This allowed the accurate placement of measurement devices to be made within the distraction gap, so that only the characteristics of the callus at this site were measured during biomechanical testing. The embedding of the specimens in an alignment jig at a standardised length close to the distraction gap ensured proper alignment and avoided artefacts due to gripping or grasping of the specimen. To ensure that the specimens were aligned with the axis of the machine they were mounted in a special jig while the ends were embedded in PMMA (Fig. 1), so that they were centered in the casting cylinders. The contralateral tibiae which had not been operated on served as the control group for the biomechanical testing. In a parallel study, the callus was treated with different combinations of growth factors and carrier material, resulting in four treatment groups plus the contralateral control group. The experiments were conducted in accordance with German Federal legislation on animal welfare.

Before biomechanical testing the deep-frozen tibiae were thawed at room temperature and kept wet using compresses soaked in $0.9 \% \mathrm{NaCl}$ during the entire test period. The jigs in which the specimens were mounted allowed compressive, four-point bending or torsion testing in a materials testing machine (Model 858; MTS Corporation, Minneapolis, Minnesota). The order of testing of stiffness was randomised, and measurements were performed on each specimen by compressive, anteroposterior and mediolateral bending and torsional stress. Loading was applied to a maximum of $15 \mathrm{Nm}$ of torque, a bending moment of $6.5 \mathrm{Nm}$ and to a compressive load of $750 \mathrm{~N}$ for the operated tibiae or to $1500 \mathrm{~N}$ for the control specimens. The resulting deformation was detected by custom-made compression, torsion and deflection sensors and a precision potentiometer (Laboratory for Biomechanics and Biomaterials of Hannover Medical School, Hannover, Germany). In a final experiment, the specimens were loaded in torsion until failure in order to record the maximal torsional moment.

In order to minimise viscoelastic behaviour, pre-cycling conditioning was carried out at the beginning of each testing procedure. During measurement, load and deformation were simultaneously recorded in order to determine stiffness, which is defined by the quotient of load and deformation. When compared with the load-deformation curve for the intact tibiae, most of the distracted tibiae showed a clearly identifiable linear region. In those which had small deviations from a linear behaviour, a tendency to a linear increase in load was seen. It was thus possible to determine stiffness from the linear region of the load-deformation curve when an initial offset was seen and before the specimens were subsequently loaded to destruction.

Measurement of torsional stiffness. The specimens were mounted in a special custom-made jig for torsional testing. The tibiae, embedded at their ends in PMMA, were mounted in metal cylinders and connected by a universal 


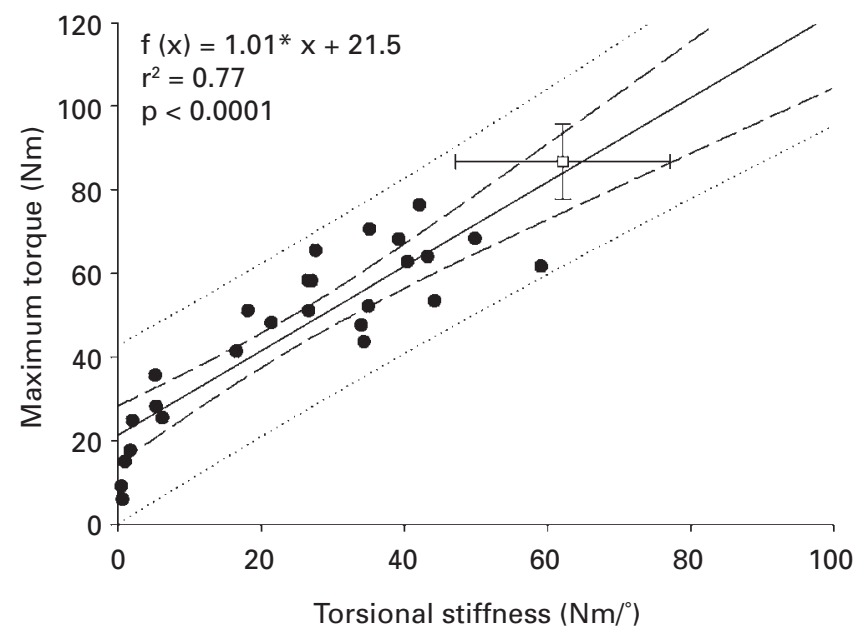

Fig. 2a

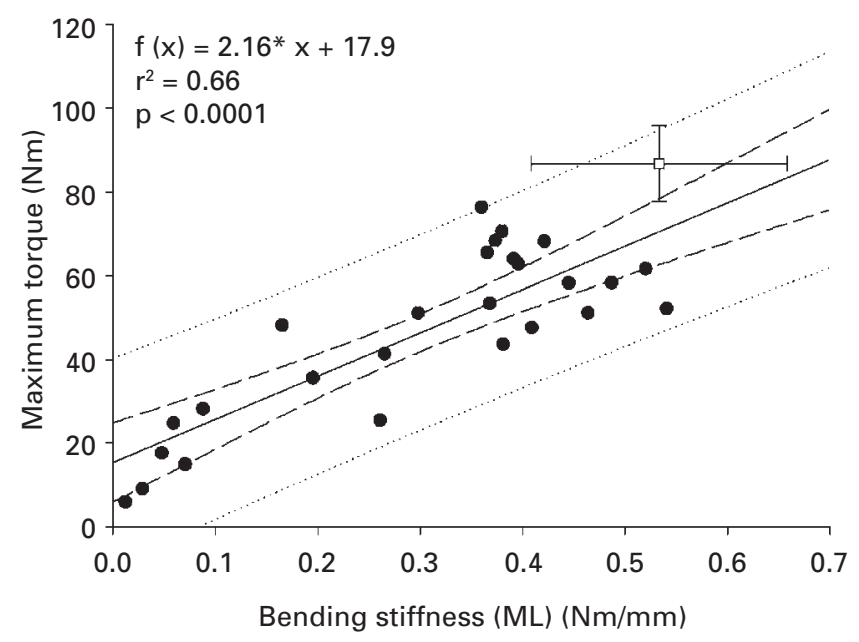

Fig. 2c

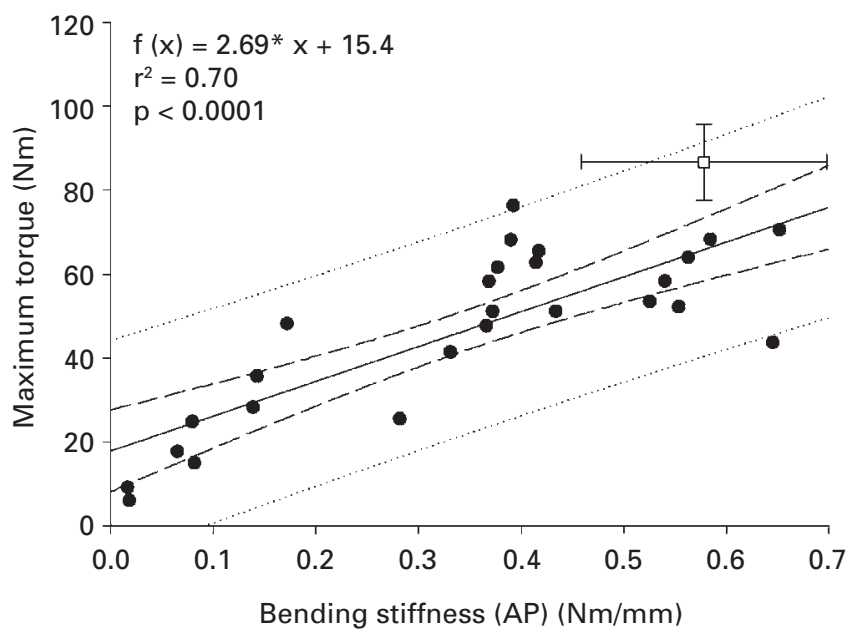

Fig. $2 b$

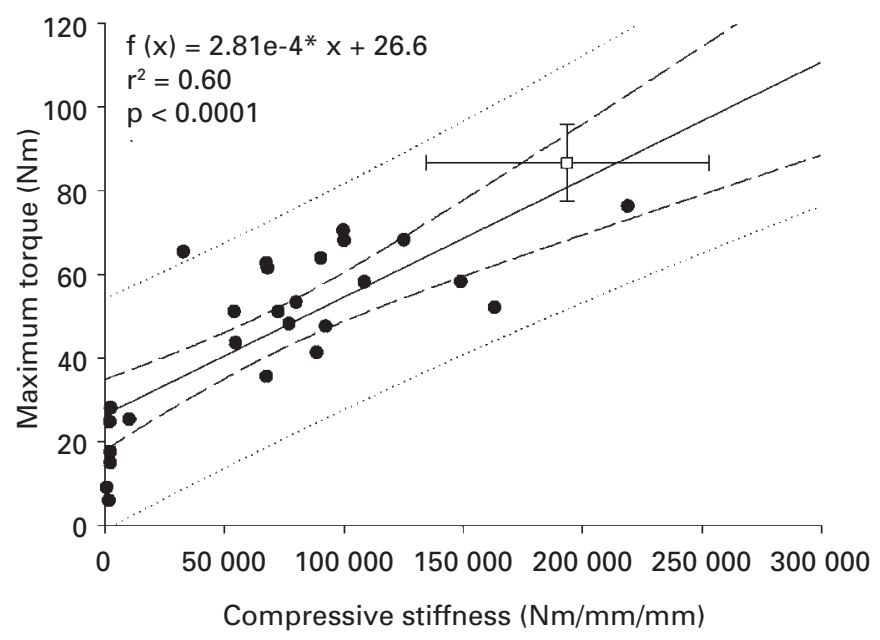

Fig. $2 d$

Graphs showing relationships a) between torsional stiffness, b) anteroposterior (AP) bending stiffness, c) mediolateral (ML) bending stiffness and d) compressive stiffness and the maximum torsional moment of tibiae treated by distraction osteogenesis. Each black dot represents the characteristics of the various distracted tibiae. The equation represents the function of the linear regression $\longmapsto$, the medium dashed lines (- - - ) the $95 \%$ confidence interval, and the dotted lines (…) the $95 \%$ predicting interval. The square ( $\square$ ) represents the mean of intact values for comparison purposes and the error bars the SD.

joint to the materials testing system. The universal joint was used in order to apply only torsional stress to the specimen.

The change in angle and the corresponding applied torsional moment were recorded. In order to measure the change in angle within the distraction gap a speciallyconstructed rotation sensor, similar to that described by McCabe et al, ${ }^{24}$ was used. The device was calibrated to the rotational displacement transducer of the materials testing system.

The stiffness testing procedure began with preconditioning of ten cycles up to a torsional moment of $5 \mathrm{Nm}$, followed by the actual testing of the specimen with the tibiae torsionally loaded up to an end-point of $15 \mathrm{Nm}$ with a speed of $0.05^{\circ}$ per second. Stiffness was calculated by the regression of the linear portion of the load-displacement curve using Origin 4.0 (Microcal Software Inc, Northampton, Massachusetts).

Measurement of compressive stiffness. The specimens were mounted in a special custom-made jig for compressive testing, similar to that used for torsional testing. A stiff connection was used to link the embedded tibiae with the materials testing system instead of a universal joint and the specimens were tested in compressive loading with rotation constrained at each end. The recorded parameters were the change in length in relation to the length of origin of the distraction gap and the corresponding force applied. The change in length was measured by a strain-gauge-based extensometer placed midway between the two inner loading points. The specimens were pre-conditioned for ten cycles at $250 \mathrm{~N}$. The change in length was then measured by loading the specimen at $0.5 \mathrm{~mm}$ per minute until a max- 


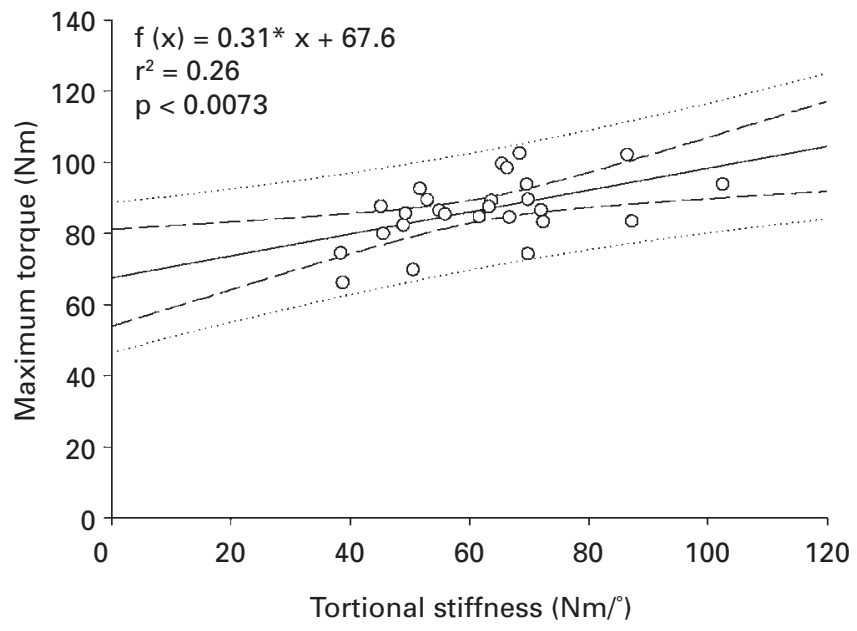

Fig. 3a

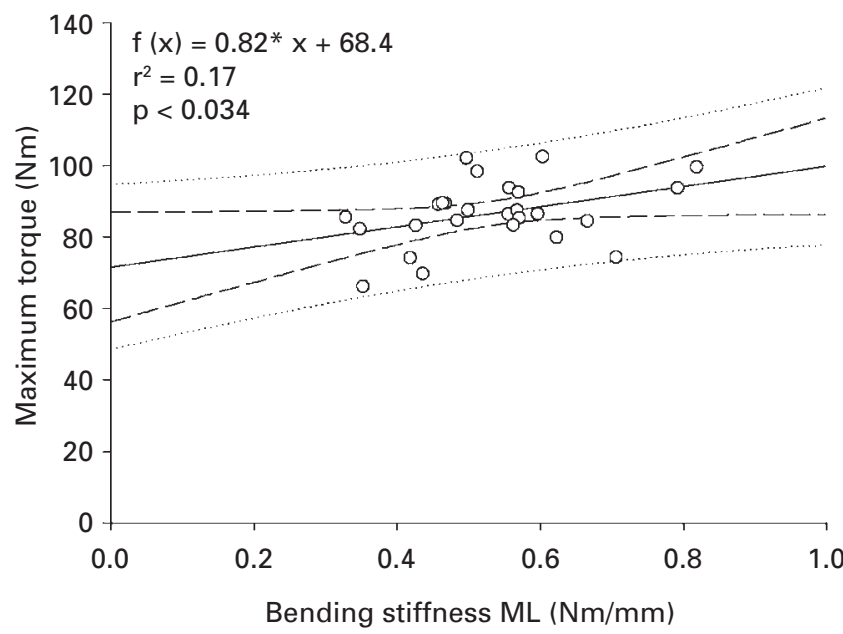

Fig. 3c

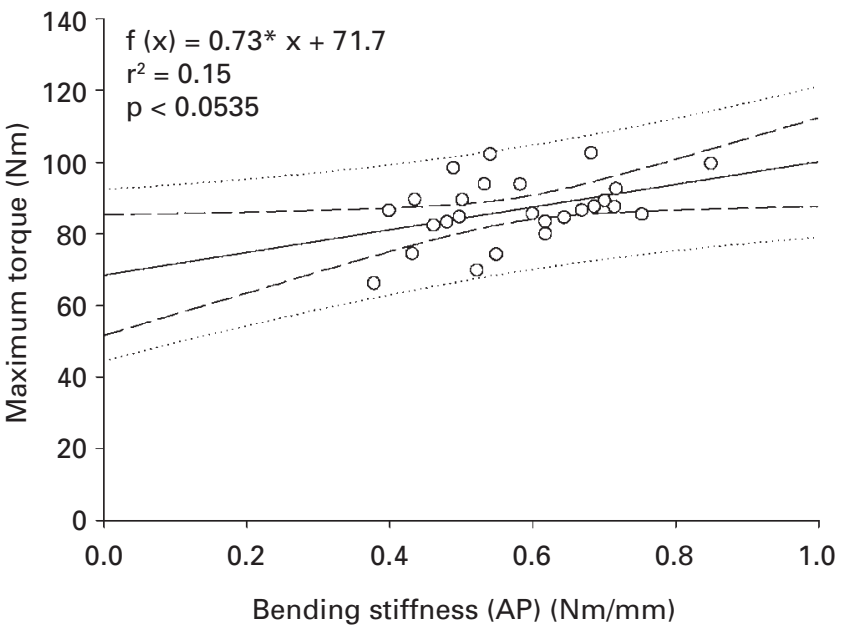

Fig. $3 b$

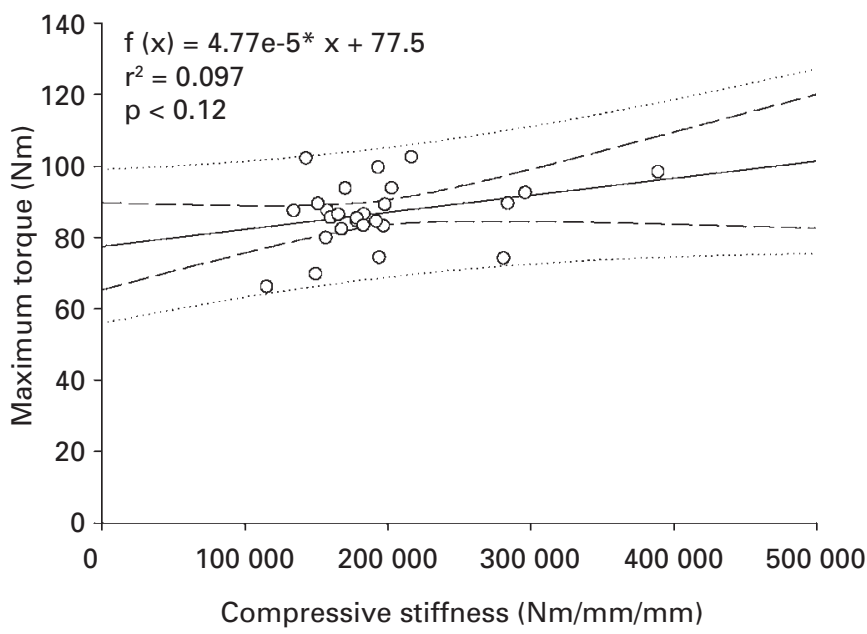

Fig. 3d

Graphs showing relationships a) between torsional stiffness, b) anteroposterior (AP) bending stiffness, c) mediolateral (ML) bending stiffness and d) compressive stiffness and the maximum torsional moment of non-distracted, intact tibiae. Each circle represents the characteristics of the various intact tibiae. The equation represents the function of the linear regression $(-)$, the medium dashed lines $(---)$ the $95 \%$ confidence interval, and the dotted lines $(\cdots \cdots)$ the $95 \%$ predicting interval.

imum load of $750 \mathrm{~N}$ for the distracted tibiae and $1500 \mathrm{~N}$ for the intact tibiae was attained. It was necessary to double the load for the control group in order to recognise a change in length of the intact tibiae.

The compressive stiffness was calculated by the regression of the linear portion of the load-displacement curve.

Measurement of bending stiffness. The specimens were mounted in a special custom-made jig for four-point-bending testing. The tibiae were positioned on the lower construct of the jig. The materials testing system applied a force to the tibiae using the upper part of the jig resulting in a bending moment. A deflection sensor measured the deflection of the tibiae, which was recorded with the corresponding bending moment applied. The tibiae were loaded at a displacement rate of $0.01 \mathrm{~mm}$ per second up to a maximum bending moment of $6.5 \mathrm{Nm}$ after pre-cycling conditioning for ten cycles up to $2.6 \mathrm{Nm}$. The deflection was measured by a specially-constructed deflection sensor. Each specimen was tested in an anteroposterior and mediolateral orientation.

The bending stiffness was calculated by the regression of the linear portion of the load-displacement curve.

Measurement of the maximal torsional moment. In a final test torsional testing to failure was applied to the tibiae at a rate of $0.05^{\circ}$ per second after pre-cycling conditioning. The ultimate torsional moment and its corresponding change in angle were recorded. Analysis of the load-displacement curve allowed determination of the maximal torsional moment.

Statistical analysis. Stiffness was calculated by regression of the initial linear (non-destructive) part of the loaddisplacement curves using Origin 4.0 (Microcal Software 
Table I. Coefficient of determination $\left(r^{2}\right)$ of each linear regression and the associated $p$ value for the distracted and intact tibiae

\begin{tabular}{lll}
\hline Stiffness & $\mathbf{r}^{2}$ & $\mathbf{p ~ v a l u e}^{*}$ \\
\hline $\begin{array}{l}\text { Torsional } \\
\quad \text { Distracted tibiae }\end{array}$ & 0.77 & 0.0001 \\
$\quad$ Intact tibiae & 0.26 & 0.0073 \\
$\begin{array}{l}\text { Bending (anteroposterior) } \\
\quad \text { Distracted tibiae }\end{array}$ & 0.70 & 0.0001 \\
$\quad$ Intact tibiae & 0.15 & 0.0535 \\
$\begin{array}{l}\text { Bending (mediolateral) } \\
\quad \text { Distracted tibiae }\end{array}$ & 0.66 & 0.0001 \\
$\quad$ Intact tibiae & 0.17 & 0.0341 \\
$\begin{array}{l}\text { Compressive } \\
\quad \text { Distracted tibiae }\end{array}$ & 0.60 & 0.0001 \\
$\quad$ Intact tibiae & 0.10 & 0.1223 \\
\hline * analysis of variance & &
\end{tabular}

Inc). The correlation of the results of the different types of measurements of stiffness with those of the strength measurements was computed using linear regression analysis. For each parameter measured an analysis of variance (ANOVA) was performed with SPSS software (SPSS Inc, Chicago, Illinois). From this analysis of each parameter of stiffness a regression line was determined as well as the correlation coefficient $(r)$ and the coefficient of determination $\left(\mathrm{r}^{2}\right)$. The greater the coefficient of determination, the greater was the correlation of the parameters analysed.

The $95 \%$ confidence interval (CI) and the $95 \%$ predicting interval (PI) were computed and expressed in Figures 2 and 3 .

\section{Results}

Our results showed a highly significant linear regression between the maximum torsional moment and the different types of stiffness for the regenerate callus of the distracted tibiae, suggesting that as the maximum torsional moment increased so did torsional, compressive and bending stiffness (Fig. 2).

The variance of the different stiffness parameters expressed by the correlation coefficient ( $\mathrm{r}$ ), and the coefficient of determination $\left(\mathrm{r}^{2}\right)$ was not wide (Table I). That of the torsional stiffness was the smallest, which was supported by a higher correlation coefficient $(\mathrm{r})$ and thus by a higher coefficient of determination $\left(\mathrm{r}^{2}\right)$. The coefficient of determination $\left(\mathrm{r}^{2}\right)$ for torsional stiffness was $\mathrm{r}^{2}=0.77$ $(p<0.0001)$ and for bending stiffness $r^{2}=0.70(p<0.0001)$ in the anteroposterior and $\mathrm{r}^{2}=0.66(\mathrm{p}<0.0001)$ in the mediolateral orientation. For compressive stiffness the coefficient was $r^{2}=0.60(p<0.0001)$.

Our results also showed lower correlations between the different types of stiffness and the maximum torsional moment for the intact, non-distracted tibiae (Fig. 3; Table I) compared with those for distracted tibiae. The coefficient of determination was $\mathrm{r}^{2}=0.26(\mathrm{p}=0.0073)$ for torsional stiffness, $\mathrm{r}^{2}=0.15(\mathrm{p}=0.0535)$ for bending stiffness in the anteroposterior and $\mathrm{r}^{2}=0.17(\mathrm{p}=0.034)$ in the medio- lateral orientation, and $\mathrm{r}^{2}=0.10(\mathrm{p}=0.12)$ for compressive stiffness.

\section{Discussion}

Our results showed a highly significant correlation between the maximum torsional moment and the different types of stiffness for regenerate callus. Thus, measurement of the torsional, bending and compressive stiffness can be used to predict the load-bearing capacity of regnerate callus. Those measurements can be used to quantify healing and to assist in determining the time for removal of an external fixator and return to load bearing.

There was less correlation between the maximum torsional moment and the different types of stiffness in the intact tibiae. The lower coefficients of correlation between the different types of stiffness and ultimate load in intact tibiae indicate that the relationship is less predictive at higher values of stiffness. This suggests that as the regenerate callus regains the stiffness characteristics of intact bone during healing the measurement of stiffness becomes less predictive of the load-bearing capacity of the healing tissue.

Our results agree with previous observations that measurements of stiffness can be used to quantify the healing of bone. Dwyer et al ${ }^{21}$ concluded after analysing bending stiffness that the stiffness of callus is a direct measure of the ability of bone to function mechanically. Chehade et $\mathrm{al}^{4}$ observed that measurements of stiffness can be used to predict strength in the early stages of healing. Hente et $\mathrm{al}^{18}$ found that bending stiffness can provide information about the healing of a fracture. Windhagen et $\mathrm{al}^{17}$ investigated a method for providing a quantitative estimate of the loadbearing capacity of the regenerate by measuring torsional stiffness in vivo.

Our observations also confirm the theoretical analysis of Roberts and Steele ${ }^{25}$ which predicted that measurement of both torsional and bending stiffness would be useful in determining the strength of callus. Although this analysis indicated that the lateral bending stiffness was more sensitive to changes in the properties of callus than torsional stiffness, our results show a greater correlation between measurements of torsional stiffness and the maximum torsional moment, and thus, by assumption, the status of the healing callus.

Chehade et $\mathrm{al}^{4}$ noticed a biphasic relationship between stiffness and strength in their experiments on fractures. Once the healing bone reached a level of stiffness equivalent to $65 \%$ of the intact bone there was no longer a correlation between stiffness and strength. Since our observations were made at a single point in time and those of Chehade et $\mathrm{al}^{4}$ were conducted over a longer period, the results are not strictly comparable. However, our experiments indicate that the measurement of stiffness as a prediction of loadbearing is more suited to regenerate callus than to the intact bone.

Previous clinical studies ${ }^{13,21,22}$ have shown that it is safe to remove external fixators once the bending stiffness of 
regenerate callus has reached approximately $25 \%$ of that of the intact tibia. A mechanical end-point of healing of the fracture at which the fixator can be safely removed has also been defined for axial loading. ${ }^{13}$ Since our results indicate that measurements of torsional bending and compressive stiffness are all suitable for predicting the healing status, we consider that the conclusions of Cunningham et $\mathrm{al}^{13}$ Dwyer et $\mathrm{al}^{21}$ and Richardson et $\mathrm{al}^{22}$ concerning bending and compressive stiffness also apply to measurements of torsional stiffness.

Our study analysed the suitability of the different types of stiffness as predictors of load-bearing capacity using a very precise measurement technique of torsional stiffness with a custom-made torsion sensor and a four-point bending device in combination with deflection measurements. A limitation of the study was that the only mode of failure tested was torsional loading. Also, the specimens were harvested at one time-point, which precluded analysis of when the method could predict the load-bearing capacity of regenerate bone.

Our results suggest that torsional, bending and compressive stiffness are suitable parameters for predicting the load-bearing capacity of healing callus tissue and can be used to quantify healing and to assist in determining the time for removal of the external fixator. This suitability of measurements of stiffness for predicting strength is much less for intact than for healing bone.

No benefits in any form have been received or will be received from a commercial party related directly or indirectly to the subject of this article.

\section{References}

1. Panjabi MM, Walter SD, Karuda M, White AA, Lawson JP. Correlations of radiographic analysis of healing fractures with strength: a statistical analysis of experimental osteotomies. J Orthop Res 1985;3:212-18.

2. Panjabi MM, Lindsey RW, Walter SD, White AA 3rd. The clinician's ability to evaluate the strength of healing fractures from plain radiographs. J Orthop Trauma 1989;3:29-32.

3. Sano H, Uhthoff HK, Backman DS, Yeadon A. Correlation of radiographic measurements with biomechanical test results. Clin Orthop 1999;368:271-8.

4. Chehade MJ, Pohl AP, Pearcy MJ, Nawana N. Clinical implications of stiffness and strength changes in fracture healing. J Bone Joint Surg [Br] 1997;79-B:9-12.
5. Webb J, Herling G, Gardner T, Kenwright J, Simpson AH. Manual assessment of fracture stiffness. Injury 1996;27:319-20.

6. Cattermole HC, Cook JE, Fordham JN, Muckle DS, Cunningham JL. Bone mineral changes during tibial fracture healing. Clin Orthop 1997;339:190-6

7. Cattermole HC, Fordham JN, Muckle DS, Cunningham JL. Dual-energy x-ray absorptiometry as a measure of healing in fractures treated by intramedullary nailing. J Orthop Trauma 1996;10:563-8

8. Reichel H, Lebek S, Alter C, Hein W. Biomechanical and densitometric bone properties after callus distraction in sheep. Clin Orthop 1998;357:237-46.

9. Augat P, Merk J, Genant HK, Claes L. Quantitative assessment of experimental fracture repair by peripheral computed tomography. Calcif Tissue Int 1997;60:194-9.

10. Harp JH, Aronson J, Hollis M. Noninvasive determination of bone stiffness for distraction osteogenesis by quantitative computed tomography scans. Clin Orthop 1994; 301:42-8

11. Schnarkowski P, Redei J, Peterfy CG, et al. Tibial shaft fractures: assessment of fracture healing with computed tomography. J Comput Assist Tomogr 1995;19:777-81.

12. Kolbeck S, Bail H, Weiler $\mathbf{A}$, et al. Digital radiography: a predictor of regenerate bone stiffness in distraction osteogenesis. Clin Orthop 1999;366:221-8.

13. Cunningham JL, Kenwright J, Kershaw CJ. Biomechanical measurement of fracture healing. J Med Eng Technol 1990;14:92-101.

14. Gruber G, Konerman W. Possibilities and limitations of ultrasonography in corticotomy/callus distraction. Orthopade 2002;31:172-5 (in German).

15. Daniel BL, Waanders NA, Zhang Y, et al. The use of ultrasound mean acoustic attenuation to quantify bone formation during distraction osteogenesis performed by the llizarov method: preliminary results in five dogs. Invest Radio/ 1994;29:933-9.

16. Richter D, Hahn MP, Ostermann PA, et al. Ultrasound follow-up of callus distraction of the tibia: technique, possibilities and limits. Chirurg 1996;67:1152-9 (in German).

17. Windhagen $\mathbf{H}$, Bail $\mathbf{H}$, Schmeling $\mathbf{A}$, et al. A new device to quantify regenerate torsional stiffness in distraction osteogenesis. J Biomech 1999;32:857-60.

18. Hente R, Cordey J, Perren SM. In vivo measurement of bending stiffness in fracture healing. Biomed Eng Online 2003;2:8.

19. Evans M, Kenwright J, Cunningham JL. Design and performance of a fracture monitoring transducer. J Biomed Eng 1988;10:64-9.

20. Aronson J, Harp JH. Mechanical forces as predictors of healing during tibial lengthening by distraction osteogenesis. Clin Orthop 1994;301:73-9.

21. Dwyer JS, Owen PJ, Evans GA, Kuiper JH, Richardson JB. Stiffness measurements to assess healing during leg lengthening: a preliminary report. $J$ Bone Joint Surg [Br] 1996;78-B:286-9.

22. Richardson JB, Cunningham JL, Goodship AE, O'Connor BT, Kenwright J. Measuring stiffness can define healing of tibial fractures. J Bone Joint Surg [Br]1994; 76-B:389-94.

23. Thorey $\mathbf{F}$, Windhagen $\mathbf{H}$, Linnenberg $\mathbf{D}$, et al. Assessment of bone healing during callus distraction by an automatic torsional stiffness metering system. Biomed Tech (Berl) 2000;45:343-8 (in German).

24. McCabe RP, Kohles SS, Chelikani SV, Vanderby R Jr. A device for measuring relative angular displacement. J Biomech Eng 1998;120:299-302.

25. Roberts SG, Steele CR. Efficacy of monitoring long-bone fracture healing by measurement of either bone stiffness or resonant frequency: numerical stimulation. J Orthop Res 2000;18:691-7. 